\title{
CORPORATE GOVERNANCE AND THE MONDRAGÓN COOPERATIVES
}

\author{
JORDI SURROCA, MIGUEL A. GARCÍA-CESTONA, AND LLUÍS SANTAMARIA
}

\begin{abstract}
This paper builds upon recent advances in the corporate governance framework to extend and complement the economic literature on producer cooperatives. We argue that the problem of governance in a cooperative is twofold and consists in designing mechanisms and setting up institutions that (1) encourage workers to define a goal that maximizes workers' welfare and (2) induce managers to pursue and internalize such a broad goal. When compared to capital-controlled firms, the agency problems become more complex and harder to solve in the cooperative framework. As empirical evidence of this problem and its corresponding solution, we illustrate the case of the Mondragón cooperatives, explaining in detail the incentive system and the control mechanisms now in place in this successful business group. The study of the governance architecture of Mondragón may help us to propose solutions to traditional problems of the cooperative firm and to reach a better understanding of both the governance of cooperatives and corporate governance in general.

RESUMEN: El presente artículo utiliza el esquema conceptual del gobierno de la empresa para completar y extender la literatura sobre cooperativas. El problema de gobierno en este tipo de organización es doble y consiste en introducir instituciones que, en primer lugar, conduzcan a los trabajadores a definir una misión que maximice la eficiencia y, en segundo lugar, que induzcan a los directivos a hacer suya dicha misión. En comparación con las empresas controladas por el capital, el problema de agencia de las cooperativas presenta una mayor complejidad y su resolución es, por tanto, más laboriosa. Como evidencia empírica de esta problemática y su resolución, detallamos los sistemas de incentivos y mecanismos de control actualmente vigentes en las cooperativas de Mondragón. Las enseñanzas obtenidas del caso nos permiten proponer soluciones para resolver los tradicionales problemas de las cooperativas, al tiempo que nos permite avanzar tanto en el estudio del gobierno de la cooperativa en particular como de la empresa en general.
\end{abstract}

The perennial subject of debate about who should manage the operations of a firm and be entitled to the benefits of these activities will probably be prolonged in the years to come. This discussion, in view of the most orthodox economists, is absolutely unjustified. In their opinion, the abundant theoretical literature that vouched for the superiority of the "capitalist formula," compared to other types of firms, is (or should be) enough to wind up the debate. Furthermore, a mere consideration of the structure of the most advanced economies seems to uphold the already referred to theoretical

Jordi Surroca is an assistant professor of management in the Department of Business Administration at Universidad Carlos III de Madrid. He holds a Ph.D. in business administration and a licentiate degree in business and economics from Universitat Autònoma de Barcelona. His research interests center on stakeholder management, firm strategy, innovation, and corporate governance.

Miguel A. García-Cestona is an associate professor of managerial economics at the Universitat Autònoma of Barcelona (UAB) and also serves as coordinator of a joint doctoral program in "Economics, Management and Organizations." He graduated from Universidad de Zaragoza and holds an M.A. in economics and a Ph.D. in business administration from Stanford University. His research interests are in the fields of corporate governance, theory of the firm, and comparative institutional analysis. arguments. However, in spite of this overwhelming evidence, many continue to advocate organizational forms in which other stakeholders, who are not the shareholders, could play a more active role. The group that is referred to most often is, undoubtedly, that of workers. Although there are different degrees of participation for workers in the company's affairs, it is widely known that the democratization of the means of production is socially and economically desirable. Producer cooperatives (as these firms are labeled according to Spanish Cooperative Law 27/1999; or labor-managed firms according

Lluís Santamaria is an assistant professor of financial and management accounting in the Department of Business Administration at University Carlos III de Madrid. He holds a Ph.D. in business administration and a licentiate degree in business and economics from Universitat Autònoma de Barcelona. His research interests include management of innovation and intangibles, accounting information systems, and comparative institutional analysis.

The authors thank Vicente Salas and Javier Mongelos. This work would have not been possible without the collaboration of top managers of Mondragón Corporación Cooperativa. The authors gratefully acknowledge financial support from the Spanish Ministry of Science and Technology (Grant SEC2003-03797) and the Spanish Ministry of Education and Science (Grants SEJ2004-08176-C0202 and SEJ2004-07530-C04-02). 
to the term employed by Bonin, Jones, \& Putterman, 1993) are the maximum expression of corporate democracy, inasmuch as workers own the assets of the firm and control the decision-making process.

Certainly, the conclusion reached in this debate is of special importance because of its implications in terms of economic policies. For example, some countries enact laws on the participation of workers on the board of directors; and firms that encourage profit sharing or shareholding schemes are given tax exemptions and other incentives. However, from our perspective, before putting forward recommendations in terms of economic policies, we must carry out a clear assessment of the economic impact on the democratization of the firm.

To this end, in the past decade, some researchers have reviewed the vast theoretical and empirical literature available on this issue (Bonin et al., 1993; Dow, 2001; Dow \& Putterman, 2000; Hansmann, 1996). The assessment this research came up with is not ambiguous: the cooperative firm has serious disadvantages when compared to the capitalist firm. However, any reader who is interested in the details of this decision can ascertain that there is no agreement among cooperative researchers on what is the real cause of the supposed inferiority of this type of firm. Furthermore, others argue that most of the disadvantages attributed to the cooperatives are more theoretical than factual, and that, in fact, cooperatives have advantages when compared to capitalist firms.

For these reasons, we shall provide, in this paper, a broad view of the main explanations provided by the theoretical and empirical literature, then we shall fill the present vacuum and propose solutions not envisaged hitherto. In order to develop this objective, we have resorted to new theoretical arguments and new empirical evidence. In theoretical terms, the literature on cooperatives has been complemented and extended based on the most recent research on corporate governance. Due to the complementary nature of both approaches, we can carry out research work on the corporate governance of labor-managed firms by pointing out the conflict of interests encountered in these firms. We shall also examine the possible institutions and mechanisms that can work toward mitigating this conflict. Empirically, we put forward the case of "Mondragón Corporación Cooperativa" (MCC). The MCC is the biggest industrial cooperative movement in the world and constitutes one of the few examples of successful democratic industrial organizations. The description of the peculiar system of MCC corporate governance will serve as a starting point for the analysis of possible alternatives. Furthermore, it will also serve as a more general reflection on corporate governance. This consideration will bring the paper to a close.

We consider that a better understanding of corporate governance problems and the way to approach them from the MCC perspective can help us to propose appropriate solu- tions that will take into account the special features of this peculiar organization. In addition, this approach can help us draw some conclusions from corporate governance for firms in general.

\section{CORPORATE GOVERNANCE: THEORETICAL CONSIDERATIONS}

\section{Does a Corporate Governance Theory of Cooperatives Exist?}

Cooperatives have been given little attention in the economic literature on corporate governance due to two main reasons. The first is that most of the research works postulate that there is no separation between ownership and corporate control, and workers, being the residual claimants, should have the right to make decisions (Hansmann, 1988). The second reason comes from the traditional framework in which the concept of corporate governance was formulated. In its most classical version, exemplified in the work of Shleifer and Vishny (1997), corporate governance centers the discussion around large corporations within the advanced economies, where the agency problem becomes more evident (Jensen \& Meckling, 1976).

Presently, the number of researchers who advocate an alternative conceptual framework to address the corporate governance problems is increasing. Some of these views state that (1) the ownership of the firm can be transferred to other stakeholders that do business with the firm, in addition to those who provide financial resources (Hansmann, 1996); (2) business decisions have consequences far beyond the agency relationship; and (3) contracts, laws, and "exit options" do not entirely protect those groups that are involved (Tirole, 2001; Zingales, 2000). This broad perspective allows us to analyze the corporate governance of producer cooperatives.

In particular, we assume that the owners of the cooperative, who are the workers, are entitled to heterogeneous preferences (Hansmann, 1996). The multiplicity of objectives of those who share corporate control will imply important policy costs when it comes to decision making, for there is a slowdown in the decision-making process, and the agency problems bring about mutual distrust. In order to reduce the costs associated with collective decision, workers delegate the daily management of the organization to managers. In this way, the disparities between different legal forms of the firm can be established in terms of which group or groups shall be involved in the decision-making process (or have the control rights) and who shall be entitled to the surplus generated by the firm (or have rights to the residual income). In a corporation, or a capital-controlled firm, the board of directors is appointed by the investors who, in principle, are entitled to the surplus. Whereas, in a workers' cooperative, the surplus 
is shared, and the governing council, which is the equivalent body to the board of directors, is elected by workers (Dow, 2001: 202).

Nevertheless, a common characteristic to consider among these organizations is the existence of an agency problem. This makes it possible to complement and extend the literature on cooperatives (for a review, see Bonin et al., 1993; Dow, 2001; Dow \& Putterman, 2000; Hansmann, 1996) on the basis of the most recent research works on corporate governance (see Shleifer \& Vishny, 1997; Tirole, 2001; Zingales, 2000).

However, cooperatives are characterized by an agency relationship with some peculiarities: the multiplicity of workers' interests will be reflected in terms of unspecified objectives that must be attained by the management of the firm. This imprecision in the definition of the corporate mission will give more discretionary power to managers to impose their own preferences to the detriment of workers' interests. In this context, corporate governance should propose mechanisms and institutions that will make it possible to eliminate or mitigate the agency problem, hence, maximizing the collective wealth so as to maximize welfare. But the multiplicity of objectives inside the cooperative makes the solution to the governance problems (through a system of incentives and corporate monitoring mechanisms) hard to implement, as has been indicated in recent research papers on corporate governance, such as that by Tirole (2001).

In spite of these theoretical limitations, the empirical evidence provides some interesting examples of institutions and entities that, even though lacking a well-defined ownership structure (for example, multiple owners without the possibility of merging their assets) or serving multiple objectives, can achieve and improve on the performance of their capitalist rivals. This evidence goes against the theoretical results that suggest just the opposite. The case we consider in this paper, the MCC, will allow us to illustrate the possible corporate governance mechanisms that can contribute to the enhancement of the competitive stand of the cooperatives. The recorded growth throughout 50 years puts the MCC in the seventh position among the Spanish business groups, with over 200 companies with a workforce of more than 70,000 people, and more than $€ 10$ billion in sales. The MCC is composed of industrial, service, and agricultural cooperatives, a cooperative bank, and a social welfare cooperative, organized into three spheres of operations-industrial, financial, and distribution (see Figure 1). The cooperatives are also sustained by a supporting superstructure offering training centers (basic education, language schools, technical schools, managerial studies, a university, and centers for cooperative education) and research facilities (research and development centers).

For the purposes of our analysis, it will be of interest to stress that the cooperatives that participate in this consortium have a system of governance quite different from other cooperatives. This is due to the successive transformations throughout the existence of the consortium. (Turnbull [1995] describes the governance mechanisms in force in Mondragón until the MCC was created in 1991.) At present, the cooperatives are characterized by a system of governance that implements a broad objective that amalgamates the interests of all the cooperative workers of the consortium. Under the system, the formula for sharing generated surplus adds fresh impetus to support a collective social welfare.

\section{Collective Decision, Delegation of Powers, and Agency Problem}

Firms are characterized by a division of labor into functions that demand different degrees of specialization and skills on the part of workers. In principle, compensation schemes are commensurate with the skills/productivity of workers. Consequently, a significant division of labor involving functions of different degrees of specialization would give rise to significant salary differences within the firm. In the same vein, the special allocation of ownership rights (corporate control rights, residual income rights; Ben-Ner \& Jones, 1995; Hansmann, 1996) of a cooperative to workers implies that when workers' preferences are heterogeneous, the decisionmaking process in which all workers participate turns out to be inefficient (Hansmann, 1988; 1990; 1996). This could be attributed to the fact that some workers, or coalitions of workers, will attempt to influence voting results (tactical vote), thereby bringing about high transaction costs (Benham \& Keefer, 1991; Hansmann, 1988). Another possible explanation is that some agreements achieved by the majority are not sustainable, in the sense that for every possible corporate policy, there is an alternative proposal preferred by a larger coalition (Hansmann, 1996).

In order to reduce the transaction costs of collective decision making, one of the most common solutions is for workers to delegate corporate control rights to a minority entrusted with the daily managing of the company. The management of the firm can be carried out by the same group of workers or can be undertaken by an outside manager hired from the labor market. In this way, the worker-controlled firm can, in practice, be similar in terms of hierarchy to a capitalist firm. Thus, the only difference between the two types of organizations would be that in a cooperative, the board of directors would be elected by the workers, whereas in the capitalcontrolled firm, it would be elected by shareholders (Dow \& Putterman, 2000: 330).

In any case, just as in the capital-controlled firm, there would be a separation between ownership and control (Hansmann, 1988). ${ }^{1}$ Workers' delegation of decision-making rights to managers may favor the latter in adopting a nonmaximizing behavior toward the interests of the workers. We 
FIGURE 1

The Mondragón Cooperative Corporation

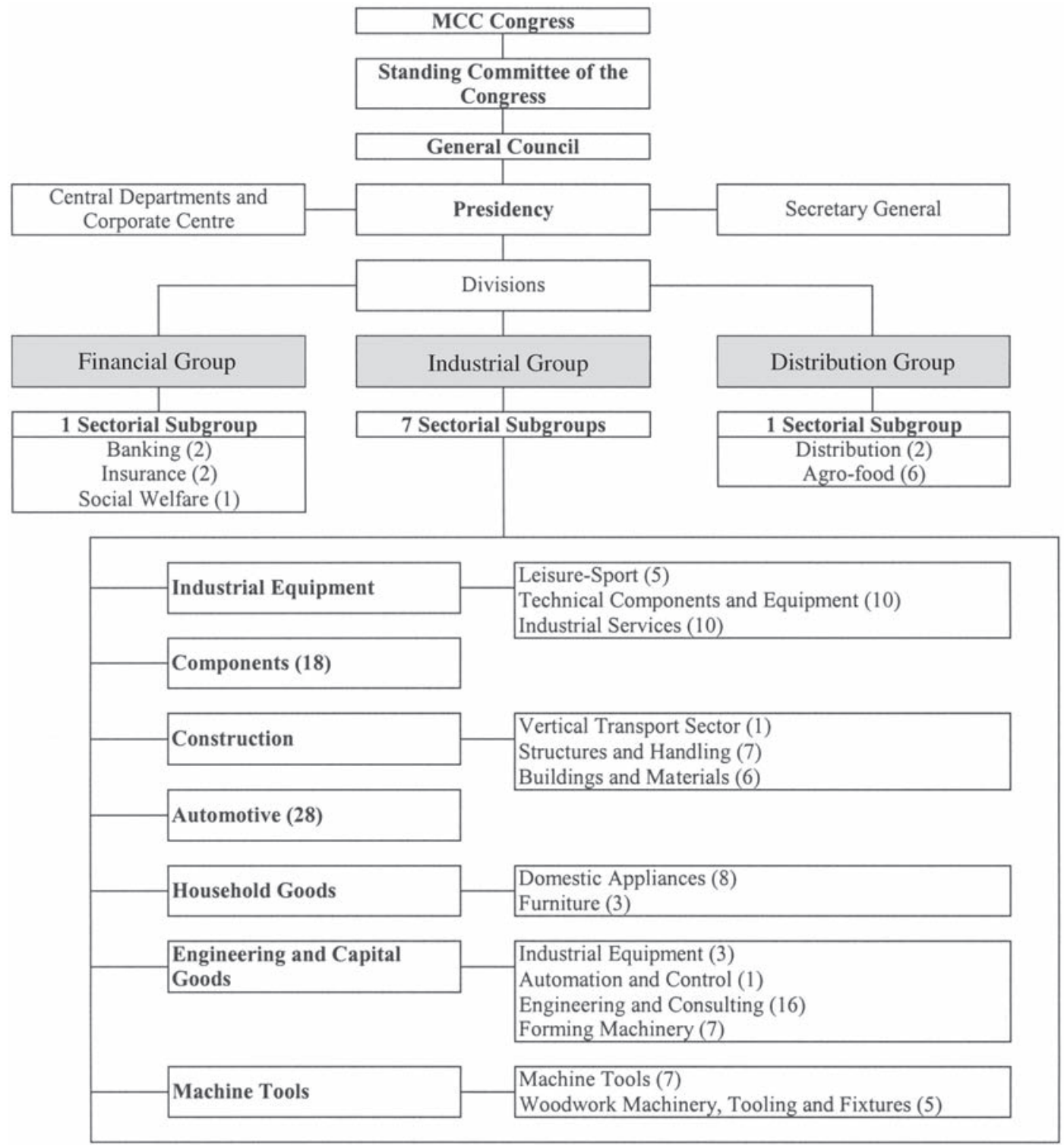

Source: MCC Annual Report (1991).

Note: The number of cooperatives is shown in parentheses.

are, therefore, faced with an agency problem that can be examined with the traditional tools of corporate governance.

However, in the cooperatives, this conflict presents certain peculiarities. In the capital-controlled firms, the aim of governance mechanisms is to induce managers to pursue shareholders' value-maximizing behavior. On the contrary, in the cooperatives, workers should first agree on its mission and on the objectives to be pursued by the firm. In this sense, in a research work on the plywood cooperatives of the Pacific Northwest in the United States, Craig and Pencavel (1993) found that the main variables of the objective function of the cooperatives are those of compensation, working hours, and workload. This result contrasts with the basic hypothesis of the literature on cooperatives that considers the maximization of worker surplus as the only argument of the objective function (Prychitko \& Vanek, 1996). 
Other problems related to the definition of the objectives have been extensively studied from a different perspective by the theoretical literature (Dow \& Putterman, 2000). This literature has analyzed the conflict of interests among workers when they decide their contribution (e.g., in terms of effort) to the cooperatives or the investment that they will make individually (e.g., specific investments in training) or collectively with the financial help of the firm (e.g., investment decisions in collective physical assets). The conclusion drawn from this literature is that, in spite of the fact that all workers agree ex ante on the objectives (in terms of effort and investments), the allocation of control rights to this group implies that they will take ex post decisions that are second-best solutions. This will have a direct impact on the ultimate efficiency of the cooperative and, consequently, on the welfare of other workers. ${ }^{2}$ Furthermore, if the skills or productivity of the workers are different and the most qualified workers do not have "exit options" (Hirschman, 1970), a transfer of wealth from the most productive to the least productive workers takes place within the cooperative. This transfer has an ex ante effect on the level of specific investments and the effort exerted by the most productive ones (Kremer, 1997). ${ }^{3}$ Moreover, this will probably contribute to the persistence of heterogeneity and the conflict of interests within the cooperative. All these arguments lead to the following observation:

Observation 1 (Imprecise mission of the firm): When the cooperative needs to elect the board of directors, workers have difficulties in providing their representatives with a coherent plan of action in order to achieve the objectives pursued by the firm (Dow \& Putterman, 2000: 331). Furthermore, the mission will be more imprecise as the interests of workers become more heterogeneous (Hansmann, 1988; 1990; 1996).

In fact, the multiplicity and the conflict of interests among workers are reflected in a lack of a defined objective to be attained by the firm. This situation deprives managers of any plan of action, makes it difficult to make decisions, politicizes the firm, and, in short, increases the power of managers to impose their own preferences, thus aggravating the conflict of interests among workers, and, ultimately, lowering the firm's efficiency (Hansmann, 1996).

Observation 2 (Extended agency problem): Cooperatives are faced with a more complex problem of corporate governance because it is a question not only of making sure that managers fulfill the objectives of the firm but of how to define a mission that maximizes efficiency.

With this observation, we want to highlight that agency problem is endemic to the cooperative because managers do not know a priori the objective(s) they have to attend to. In other words, through the voting mechanism, workers have to come to an agreement on the objective that the firm needs to pursue. It is only after members of the cooperative have came to an agreement that the mechanisms of corporate governance could be put in place to help resolve conflict among owners (workers) and managers. Therefore, the mission to be pursued and the mechanisms that must guarantee that managers take interest in pursing it depend on the outcome of the voting policy. At any rate, it is not possible to infer a priori what the result will be.

Transaction costs of collective bargaining and the possibility that managers make decisions that do not maximize efficiency will probably have a negative impact on the current value of the cooperative's investments. For this reason, it is difficult to carry out new projects financed by outside investors when the firm will not be able to meet its obligations for lack of sufficient income (Tirole, 2001: 29). This problem is aggravated by the fact that employees are risk averse, and they have limited wealth (Dow \& Putterman, 2000). ${ }^{4}$

\section{The Problem of Corporate Governance in the Cooperatives and Its Resolution}

Before identifying the institutions that can solve or mitigate conflicts of interests among employees (in the process of defining the mission) or conflicts among employees and managers (in the phase of achievement of the mission), it is imperative to point out the characteristics of the property rights of cooperatives. According to the terminology coined by Fama and Jensen (1983), cooperatives belong to the domain of "closed corporations." Therefore, their decision rights are restricted - that is, they are not freely transferable and they do not confer on the owners' indefinite rights to the cash flows (in particular, these rights cease to be valid in the cases of retirement or termination). The restrictive nature of the rights implies that there cannot be a complete separation between the functions of risk assumption and decision making, at least not to the extent that such separation between ownership and corporate governance occurs in firms that belong to the domain of "open corporations." Consequently, cooperatives cannot attain high levels of risk diversification, more so if we take into account that employees put all their human capital and most of their financial capital in the same firm. Furthermore, it is possible that employees may have opted for specific investments, in addition to investments in housing, social relations, and the employment of other members of the family (Hansmann, 1988: 292). The restrictions on the free transfer of the owner's status (there are no "exit options") and the noncentralization of control rights make it difficult to arrive at a consensus when it comes to decision making. As a result, there is an obstacle to the existence of an organized market of control rights able to coordinate managers' performance or to undertake certain monitoring activities like that of takeover bids. On the other hand, it is difficult to make 
long-term employment contracts that are entirely void of risks (Hansmann, 1988: 294), and exercising the "exit options" remains restricted due to the nonexistence of a membership market (Dow, 2001).

When it is not possible to protect interests through the "exit options" or through contractual safeguards, the corporate governance will have to design incentive mechanisms or assign "voice" to the groups involved (the "shared control"). Therefore, we define the problem of corporate governance of a cooperative in the following terms:

Definition: The corporate governance of a cooperative consists of designing mechanisms and setting up institutions that encourage workers to define a goal that maximizes workers' wealth or welfare (first level of governance) and, furthermore, induces managers to internalize such goals (second level of governance).

In this definition, we would like to call attention to the subtle difference in the problem of corporate governance between a cooperative and a capital-controlled firm. In fact, the core problem can be traced to the agency problem that exists between shareholders and managers. In this context, the capitalist corporate governance needs to suggest mechanisms or institutions in order to settle an agency problem and to induce managers to internalize the objectives of shareholders. That is, the value of the firm or the welfare of shareholders is the goal. Therefore, in a capital-controlled firm, the problem of corporate governance is centered at the second level, for there is unanimity among shareholders about what should be the goal of the company.

In the cooperative, the solution to this dual problem of corporate governance is obtained by guaranteeing that the interests of all the workers are met. One way by which the welfare of all of them can be incorporated into the decisionmaking process of the firm would consist in moving from an objective function with a single argument (e.g., to maximize surplus per worker) toward a multidimensional-objective function that integrates the welfare of the different groups of workers (Tirole, 2001). Now, the question becomes how to implement such an objective function. In other words, what corporate governance mechanisms would induce the managers to internalize this multidimensional mission?

Maximizing collective wealth and welfare in cooperatives will come as a result of the following elements: (1) the effectiveness of internal corporate governance mechanisms, such as incentive contracts, corporate governing bodies, monitoring structures or corporate culture (mutual monitoring, pressure groups, solidarity, philanthropic groups, etc.); or (2) external corporate governance mechanisms, such as competition in the product and input markets (basically, the managerial input), as well as the legal framework. We want to emphasize that due to the legal configuration of the coopera- tive firm, the market for corporate control is a governance mechanism not available for disciplining management.

A common practice in the capital-controlled firms geared toward streamlining the objectives of shareholders and the decisions of managers is to link their compensation to the growth of profits. To implement this measure in the cooperatives implies that managers' compensation will be linked to some global welfare measures. However, at the time of drawing up these incentive contracts, one is faced with the difficulty of incorporating adequate indicators of such welfare. This situation contrasts with the ease with which welfare indicators, such as book profits or share price trend of shareholders, are invoked in a capital-controlled firm. Consequently, if the welfare of a group of workers is easier to measure than other group's welfare, managers will focus their attention on the maximization of this objective to the detriment of other objectives (Holmström \& Milgrom, 1991). This implies that when the objective function of the firm is not well defined due to measurement problems, it is recommendable that managers' compensation be fixed (that is, should not be linked to welfare indicators). Ambiguity in the collective welfare indicators also undermines the effectiveness of implicit incentive systems such as promotion, for the market does not know which indicator must be considered or which objective is pursued when it comes to appraising the manager's performance.

In spite of these theoretical predictions, the empirical evidence points out examples of cooperatives that have provided viable solutions to all the aforementioned problems.

\section{Corporate Governance of the Mondragón Cooperatives}

The case of the MCC constitutes one of the most impressive and successful examples of industrial cooperatives. This raises a theoretical and empirical question of interest as to why the MCC constituent cooperatives are so successful. The explanation provided in this section, which is complementary to others previously referred to in Whyte $(1995 ; 1999)$ and Whyte and Whyte (1991), states that the success of the MCC is based on the mechanisms of corporate governance, developed over more than 40 years. In this paper, we take into account these points when studying the system of incentives and the corporate governance mechanisms that are currently operational in Mondragón. The internal corporate governance mechanisms of an individual cooperative are characterized by integrating, in addition to the interests of its own workers, the interests of other workers who belong to the constituent cooperatives. The result is a complex structure of residual rights and corporate control rights that contribute to lowering the two governance conflicts, as previously pointed out. Thus, we take into account the conflict of interests among workers when it comes 
to defining the best mission (first level of governance), and the conflict between management and workers when it comes to guaranteeing that such mission is fulfilled (second level of governance).

\section{A HISTORICAL PERSPECTIVE}

The Mondragón cooperative experience started in 1956 when the first cooperative was created under the name Ulgor (currently known as Fagor). The founders of this cooperative gave authority to the workers to choose their governing bodies (Whyte, 1999). This initiative came to be the nucleus onto which other cooperatives of diverse nature were aggregated. On the whole, they were suppliers of Ulgor and drew inspiration from its organizational features.

In 1959, the creation of Caja Laboral Popular (henceforth, $\mathrm{CL}$ ) marked an important milestone in the existence of the group. This financial cooperative was established to take care of the financial and consultancy needs of the cooperatives and its members. CL played a fundamental role in the consolidation and expansion of the Mondragón cooperative movement, soon becoming the main link and the backbone of all the cooperatives that were created during the 1960s and 1970s. In fact, the group distinguished itself by linking these cooperatives to $\mathrm{CL}$ within the framework of an exclusive relationship in which the cooperatives could only transact with CL, and where the CL provided the cooperatives with all the financial and consultancy services. However, this close bankfirm relationship revealed a problem of concentration of risks. The agreements signed with CL seriously restricted the bank's ability to discipline these cooperatives, mainly due to the difficulty encountered by the institution when dissolving or liquidating cooperatives under financial distress, which were either founders of the bank or firms created and nurtured by CL (García-Cestona, 1996).

Throughout the 1980s, the organization of the group underwent a process of changes that culminated in a new arrangement-the Mondragón Cooperative Group. The main goal was to carry out a better coordination of these cooperatives so as to benefit from the presence of synergies, the implementation of new mechanisms of governance that facilitated control tasks by the group and further independence for the cooperative bank. This process culminated in the foundation, in 1991, of the MCC.

The creation of the MCC entailed a considerable transformation of both CL and the group, so as to satisfy the need for converting CL, gradually, into a commercial bank that transacts with third parties outside the group, as explained in Ormaetxea (1997). In this way, the risk associated with the close relationship between $\mathrm{CL}$ and the Mondragón cooperatives, and caused by the bank's limited ability to discipline an individual cooperative, was severely reduced. ${ }^{5}$ The ultimate outcome of this process was the transfer of the promotion and monitoring activities, formerly carried out by CL, to the MCC.

But the creation of the MCC did not only entail a new configuration of the group. Just as Ormaetxea (1997) indicates, by the end of the 1980s, the cooperative group had no capacity to intervene in the corporate policy of the individual cooperatives. Furthermore, many top managers of the group were aware of the possibility of taking advantage of the presence of important synergies, especially among those cooperatives belonging to the same sector of activity.

As a result of the creation of the MCC, the transformations in the organizational structure of the group brought about the appearance of divisions and sectorial subgroups where the constituent cooperatives were allocated based on their products and market similarities. Consequently, the intervention capacity of the MCC in the business units was increased. In Figure 2, the control architecture of the MCC is shown. Nevertheless, these cooperatives continued to be autonomous bodies, and, as such, they were free to accept or reject the agreements signed with the MCC. In this sense, the shifting of control rights to the MCC from the cooperatives was based on the idea that the latter would realize the fact that this would imply a greater ability to generate wealth and a better distribution of the surplus. In order to encourage the acceptance of the new organization, the MCC offered a series of complementary resources in terms of financial, technological, and managerial support, along with training facilities to the joining cooperatives.

For the purpose of studying corporate governance mechanisms of cooperatives, evidence will be provided about how the constitution of the MCC brought about the integration of institutions that helped in the resolution of the dual problem referred to in the previous sections. To be precise, the MCC incorporated institutions that (1) prompted cooperative members to define a mission that maximizes the collective wealth and (2) prompted managers to internalize such a mission.

\section{Institutions for Defining a Mission That Maximizes Collective Wealth}

In the theoretical approach, it has been defined that one of the problems of cooperative governance (first level of governance) consists of setting up mechanisms and institutions that help workers to define a mission that maximizes collective wealth. On the other hand, in the presentation of this case, it has been explained that prior to the constitution of the MCC, there was hardly the possibility for the group to intervene in the corporate policy of a single cooperative. For this reason, the top managers of different cooperatives were aware of the lost synergies and the missing opportunities for a better coordination. This notwithstanding, the constitution of the MCC meant the appearance of a series of mecha- 
FIGURE 2

Control Mechanism in the Mondragón Cooperative Corporation

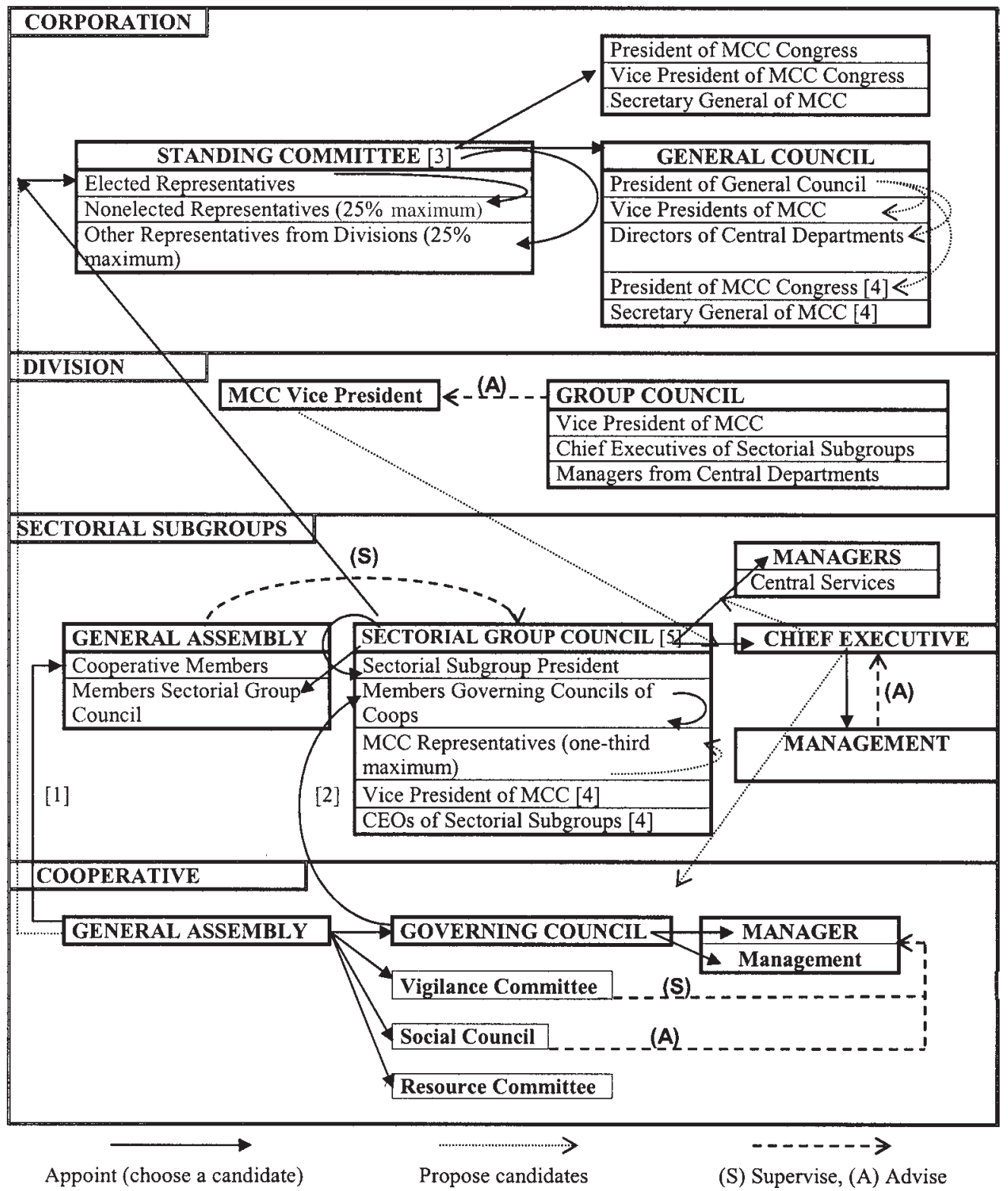

Source: Authors' elaboration with the synopsis of valid norms passed by the MCC congress (MCC, 1995).

Notes: 1. In proportion of the number of members. 2. One and three representatives for cooperative according to the number of members. 3. A maximum of 30 percent of representatives per division. 4. With voice, but without voice. 5. In CL and Lagun-Aro (they form their own sectorial subgroup), the sectorial group council is constituted by their own governing council.

nisms that enhanced the creation of collective wealth. This was achieved by (1) coordinating the activities of the individual cooperatives, (2) implementing collective policies through a system of shared control, and (3) establishing the necessary incentives in order to obtain the involvement of the constituent cooperatives.
Coordinating the activities of the constituent cooperatives. Figure 2 shows the control architecture and the coordination mechanisms of the MCC. The sectorial subgroups, divisions, and the MCC general council are entrusted with drawing up a common strategic policy and ensuring its fulfillment through the nomination of managers who must pur- 
sue the implementation of such strategy. The business units, which are the constituent cooperatives, inform the managers (i.e., chief executives) of the sectorial subgroup about their objectives and activities. The latter are entrusted with codifying, selecting, and transmitting the most important information to the vice president in charge of that sectorial subgroup. In addition, the vice president centralizes the information proceeding from other sectorial subgroups accountable to him or her. He or she, in turn, transmits the most important information to the president of the general council, which is the final authority entrusted with drawing up the plan based on all the information culled from the general policies of the MCC as a whole.

Once these general policies are formulated, this information will be transmitted to all the divisions and sectorial subgroups. From that point, the chief executive of each sectorial subgroup will be responsible for converting the objectives or plans gathered from the division into concrete and centralized plans for the constituent cooperatives. He or she will also be expected to monitor the fulfillment of these plans. Therefore, the data for drawing up the global strategy of the MCC comes from each of the constituent cooperatives.

\section{Implementation of the general policies through shared}

control. The second conclusion drawn from the analysis of the MCC monitoring and control systems portrayed in Figure 2 is that the constituent cooperatives have transferred some decision rights to the managers of sectorial subgroups, divisions, and the MCC general council.

In principle, the individual cooperatives are free to pursue their own interests, but on joining the MCC, they are, in fact, shifting control rights to the sectorial subgroup because the nomination of the cooperative manager and his or her followup must be done now by the chief executive of the subgroup. Moreover, prior to his or her nomination by the sectorial group council, the chief executive has been proposed by the MCC vice president in charge of the division, who has been nominated by the standing committee of the MCC congress. Therefore, this sequence of nominations for the positions of managers by the representatives of the MCC, division, and sectorial subgroup entails an intervention in the affairs of the constituent cooperatives through the election of the person responsible (that is, the manager) for the policy implementation. In addition, the decisions of the cooperative must be in accordance with the corporate strategies, at the corporate and at the division and subgroup levels. Furthermore, in the event of not adhering to the broad guidelines stipulated in the corporate strategic plans, there are mechanisms for sanctioning the cooperatives, including dismissal from the MCC as a last resort.

Incentives for joining the MCC. As has been previously posed, the participation of the cooperatives in the MCC project is not mandatory and it must be voted and approved by the cooperative members. Therefore, the fact that workers accept to delegate control rights must be explained in terms of achieving a higher added value when joining the MCC. In fact, when interviewed, the managers of cooperatives state that the MCC provides them with a brand image and greater accessibility to a series of corporate institutions such as collateral entities (Caja Laboral), social welfare (Lagun-Aro), research centers (Ikerlan, Ideko, or MTC), training centers (Otalora, for training managers), and an array of corporate support services (such as financial management, technical and quality development, internationalization expertise, etc.).

Another key element for obtaining the involvement of the individual cooperatives and, especially, for reinforcing the achievement of the common objectives defined in the strategic planning is the fund named "Fondo Central de Intercooperación" (Central Fund of Intercooperation). This fund is managed by the MCC board of directors, and its objective is to reward those who put into practice the corporate policies and strategies suggested by the MCC. This is achieved by reinforcing the financial capacity of the constituent cooperatives.

However, when the generation of collective wealth is not enough to guarantee the participation of workers in organizing the project, it is necessary to convince workers that the rules for sharing the generated wealth will benefit them, or, at least, that they will not be worse off. In this context, it is worth highlighting the rules on surplus sharing (see Figure 3). In addition, the policy of fixing "advance payments for labor" on the basis of market criteria has the objective of encouraging workers to be more diligent. ${ }^{6}$ Finally, through the "normativa sobre el tratamiento del capital social y distribución de los resultados" (norms on the use of equity and rules of profit sharing), the necessary incentives are provided so as to promote capital accumulation. In particular, it is achieved through the interest rates paid to capital and the regulations on the distribution of surplus sharing. It is also important to encourage cooperation among these cooperatives through the "reconversión de resultados" (reconversion of results), which is a key element for strengthening the links between the constituent cooperatives. With the "reconversion," the income of an individual cooperative no longer depends exclusively on its own operations. Rather, the results increase or decrease in relation to the results of the other cooperative members in the same sectorial subgroup, same division, and, in some cases, the same regional subgroup. In particular, each cooperative contributes a percentage of its results to a pool formed by all the MCC; later on these funds are distributed among the cooperatives depending on size and workforce. On the other hand, the implementation of a measure such as this is not easy and it has a cost, for it can encourage individual cooperatives to exhibit opportunistic behavior. If the results of a cooperative are 
FIGURE 3

Distribution of Surplus of an Individual Cooperative

\section{Gross Surplus}

\pm Reconversion of results

\begin{tabular}{|lll|l}
\hline Divisional level & $\Rightarrow$ & $5-20 \%$ of gross surplus \\
\hline Sectorial level & $\Rightarrow$ & $10-30 \%$ of gross surplus
\end{tabular} \mid$\rightarrow \begin{aligned} & \text { Whole threshold: } 40 \% \\
& \text { of gross surplus }\end{aligned}$

-Corporate income tax

Net Surplus

-Losses of previous years

\begin{tabular}{|c|c|c|c|}
\hline \multirow[t]{6}{*}{ Available Surplus } & \multirow[t]{5}{*}{$\rightarrow$} & \multirow{2}{*}{$\begin{array}{l}20 \% \\
10 \%\end{array}$} & \multirow{2}{*}{$\begin{array}{l}\text { Mandatory reserve fund } \\
\text { Education and development fund }\end{array}$} \\
\hline & & & \\
\hline & & \multirow[t]{3}{*}{$30-70 \%$} & Cooperative rebates \\
\hline & & & Monetarized profit ( $30 \%$ maximum) \\
\hline & & & Capitalized profit (the rest) \\
\hline & & The rest & Voluntary reserve fund \\
\hline
\end{tabular}

Source: Synopsis of valid norms of the MCC congress (MCC, 1995).

Note: Gross surplus is the income before taxes and after paying the interests on capital.

determined as a proportion of the total results of the sectorial subgroup, division, or regional subgroup, then the results of the group become a public good subject to moral hazard considerations.

\section{Institutions for Inducing Managers to Internalize the Mission}

Once the mission of maximizing collective wealth is defined by all members of the cooperative (first level of governance), the next problem consists of inducing the manager to internalize this mission (second level of governance). The MCC experience provides us with a system of incentives and supervision mechanisms that make it possible to find a solution to this second problem.

Managers' incentives to achieve the cooperative mission. The compensation practices have changed substantially in recent years, especially if we focus on the compensation of MCC top managers. In the past, there was a compensation limit that reduced the differences among cooperative members: the highest compensation could not exceed 4.5 times the lowest one (this ratio was 1:3 at the creation of the first cooperative). Now, it has been replaced by a manager's compensation, which is about 70 percent of the market compensation. This economic change has also been accompanied by an improvement in the social status of managers, and some former top managers have taken up important positions in institutions of the Basque government later in their lives. On the other hand, these important managerial tasks are carried out, almost exclusively, by people who have been working in the cooperatives for many years. Internal promotion and career concerns are important elements here. The appointment of managerial positions is the responsibility of the top managers of the MCC, such as the vice presidents. Consequently, it can be said that the performance of managers is enhanced, first, by the explicit incentive of a compensation that is stipulated in the policy of the MCC. According to this, the wages for functions of responsibility are linked with the productivity of the managerial input. Second, performance is also enhanced by the implicit incentive of getting promoted inside the MCC with the possibility of occupying jobs of greater responsibility within the organization (career concerns). This possibility can occasionally serve as a gateway to a more favorable labor market and, sometimes, as a gateway to the political arena.

Monitoring mechanisms to achieve the cooperative mission. The normal running of the cooperative is the responsibility of the manager, who is accountable to both the vigilance committee, which represents the interests of all workers, and to the chief executive of the sectorial subgroup, who repre- 
sents the interests of the MCC. Therefore, the manager of the cooperative is monitored in two ways-by the members of this cooperative (internal monitoring) and by the MCC (external monitoring).

With regard to internal monitoring, the vigilance committee is the body entrusted with the follow-up of decisions and results of the manager. Later, the committee informs the general assembly of its performance. Then, it is the responsibility of the governing council to replace the members of the board of directors or even the manager if necessary.

With regard to external monitoring, the strategic plan of the sectorial subgroup must be reflected, at the cooperative level, in the strategic plan of the individual cooperative, which is carried out through annual management plans. In this way, the annual management plan constitutes a key tool for the MCC at the time of monitoring the performance of the cooperative, for it incorporates both quantitative and qualitative indicators that are subject to a follow-up. When the actual results fall short of the estimated figures, the board of directors of the sectorial subgroup can recommend to the governing council the replacement of the manager.

\section{IMPLICATIONS AND NEW PERSPECTIVES IN THE STUDY OF CORPORATE GOVERNANCE}

In this study, the literature on cooperatives is complemented and extended by using the conceptual framework of corporate governance. In our opinion, the problem of governance of this type of organization is twofold. The first issue consists in guaranteeing that a mission that maximizes efficiency is defined, whereas the second issue is how to implement this mission in a successful manner. The solution to the dual problem of governance is comparatively more complex in a cooperative firm than in a typical capitalist firm. With regard to the definition of the mission, a greater multiplicity of workers' interests increases the costs of collective decision making. And, concerning how the mission can be achieved, the multiplicity of owners can lead to opportunistic behavior on the side of the management, and, as a result, the agency problem will be more severe. Through the case of Mondragón, we have tried to illustrate how governance mechanisms perform in an organization that is often presented as the paradigm of success of the cooperative firm. The case is of greater importance when we consider that these cooperatives undertake the greater share of their activities in the industrial sector, in which, according to the literature, the cooperative formula would have less competitive advantages.

The theory sustained in this paper postulates that the success of the MCC can be explained, to a great extent, by the success of its system of corporate governance, which has continued to adjust itself throughout the years, until reaching its present features. The cooperatives that form the group have a broad mission that integrates the interests of different cooperative workers who are also stakeholders of the MCC group. Workers have been able to express their views and interests in the process of drawing up the MCC's strategic policy in which all the cooperatives participated. Afterward, this general policy is formulated into strategic plans, first, for the divisions; then, for the sectorial subgroups; and, finally, for the joining cooperatives. But, how have they achieved the welfare maximization of the different stakeholders involved? To answer this question is, from our perspective, tantamount to solving the dual problem previously mentioned: (1) how can we succeed in defining a mission that maximizes collective welfare? and (2) how can we induce managers to pursue this mission?

The solution to the first problem was achieved by a voluntary shift of decision rights from the cooperatives to the MCC. Through this delegation of powers, the MCC executive commission (board of directors) was free to draw up a common strategic policy for the entire group. This is the only way to guarantee the fulfillment of the objectives of all the workers and to coordinate, at the same time, the activities of the cooperatives that belong to the group. In order to adapt the management of each cooperative to this framework, the MCC relied on its authority and on its maneuvering ability to name and replace managers, who represent the interests of the entire MCC group inside a given cooperative. Obviously, the delegation of decision rights made by the workers must be accompanied by some compensation in terms of higher results for them. In this regard, the regulation on surplus sharing constitutes a powerful incentive mechanism (and a form of risk sharing), which facilitates the workers' participation in the MCC project. Internal regulations also help in the resolution of conflicts of interests that emerge when it comes to defining the mission (i.e., levels of labor and investments and an adequate capitalization of the cooperative). We also observe that the problem of collective decision making has been partly solved through the delegation of power within the cooperative, and partly by the external pressure coming from the strategic plans.

The incentive mechanisms and the group monitoring have had a positive effect on the resolution of the second governance problem: the internalization by managers of the objectives included in the mission. With regard to shared control, the manager's performance was evaluated, taking into account (1) the achievement of the goals of the entire MCC, particularly the interests of workers of other cooperatives, and (2) its ability to satisfy the goals of the cooperative members. Concerning the first dimension, the manager is accountable to the chief executive of the sectorial subgroup. Whereas, in the second dimension, cooperative members can assess the fulfillment of their own objectives through the resource committee, the social council, and, ultimately, the general assembly. Shared 
control has been accompanied by a system of incentives that have induced managers of individual cooperatives to internalize the mission defined by (the managers of) the group. In this sense, we have identified a substantial change in the compensation practices, especially since the creation of the MCC as a corporation. The result has been an improvement in both the social status of managers and in their economic compensation. The possibility of getting along in the MCC (internal promotion) and, subsequently, opting for higher compensations, which are about 70 percent of the market compensation for similar positions, has been instrumental in getting the managers involved. Furthermore, the possibilities of promotion are not limited to the MCC, and some former top managers have become top civil servants in institutions of the Basque government.

An alternative explanation for the MCC success, which complements ours, is provided from the perspective of external governance mechanisms: the competitiveness in the product markets and the legal regulation constitute a powerful governance mechanism, although they have not been studied in this paper. An interesting feature of this case study is that, unlike other cooperatives (as is often the case in professional services) outside the group, Mondragón cooperatives are present in sectors different from those in which, in principle, this type of enterprise enjoys certain advantages. In fact, many of the cooperatives that form the MCC are industrial in nature and participate in competitive markets where the demand of efficiency is high. Nevertheless, the pressure from the product market or the regulation itself does not explain why these organizations include in their mission objectives or goals that involve some sacrifice in terms of economic efficiency.

The success of the MCC governance mechanisms is also based on the group's ability to keep growing. On one hand, the participation of the cooperatives in the project is facilitated by the resources and information they obtain from the group. On the other hand, a well-functioning incentive system for managers is closely related to the existence of growth. Both promotion opportunities and the variable compensation component depend on the presence of favorable results of the whole group. This raises doubts about the performance of control mechanisms in the event of widespread negative results.

\section{Implications for the Research on Cooperative Governance}

If worker ownership causes policy costs due to the collective election, efficiency can be improved upon by incorporating a new stakeholder into the monitoring mechanism, one with interests that are more in tune with the maximization of economic efficiency. In Mondragón, the MCC plays this role, and this is carried out with the help of the cooperative manager, who is entrusted with pursuing the workers' objectives and maximizing their utility functions. Concurrently, he or she is responsible for collective wealth maximization. It is obvious that maximizing wealth will be to the greater benefit of all workers. But, without the MCC pressure on the cooperative decisions, workers will suffer more from moral hazard when adopting decisions. The delegation of some decision rights by cooperative workers to other stakeholders (in our case, the MCC) must be accompanied by the proper incentives in order to enhance organizational transformation. Generating more wealth is not enough; it must be shared in a way that allows initial owners not to be worse off. Through this delegation of certain rights to other groups-for example, to financial suppliers - the cooperatives could start to overcome their traditional financial problems.

In short, a possible solution to the limits of industrial cooperatives would be to move toward a hybrid model of governance, in which workers joined efforts with another stakeholder whose interests are more in tune with the maximization of economic efficiency. One stakeholder that could play such a role would be a financial supplier.

Obviously, this would affect the autonomy of labor, even though incorporating this stakeholder into the monitoring process could be undertaken in a way similar to the German case. In Germany, there are two types of limited liability companies, Gesellschaft mit beschräukten Haftung (GMBH), for unlisted companies, and Akitiengesellschaft (AG), for listed companies. One special feature is that both corporate bodies face the legal obligation of creating a dual-level board. The first level is the supervisory board, or aufsichstrat, which is entrusted with monitoring the managers, and the second is the management board, or vorstand, which is responsible for the daily management of the firm.

It is important to highlight that workers' representatives and those members elected by shareholders, and who are not employees of the firm, have equal shares in the supervisory board. These counselors, elected by the shareholders, are equivalent to the external consultants of firms in the United States. In general, they come from other commercial and financial firms that have a long-term and significant relationship with the firm. For the purposes of our work, it is important to stress that with this special configuration of the supervisory board, the fulfillment of the interests of other groups are then protected and monitored.

Likewise, a dual-level structure could be employed in the case of producer cooperatives. The management board would still be the daily managerial body, with the manager at the helm of affairs. However, in the governing council or the vigilance committee, there would be room for other stakeholders representing the interests of other input suppliers, such as the financial suppliers. 
Implications for the Research on Corporate Governance

We believe that focusing the analysis on the cooperative instead of the traditional capitalist firm has some advantages. Zingales (2000) argues that the recent changes in the nature of modern corporations entailed an increase in the importance of specific investments of the different stakeholders that participate in the corporation. In fact, human capital in some of these firms has been converted into a key asset. This phenomenon also occurs in the case of investments by other stakeholders, such as in the case of suppliers. The firm has a wider scope, and the governance approach now focuses on conflict prevention among stakeholders, so as to prevent such problems from bringing the firm to a standstill or, worse, from jeopardizing its existence. For this reason, the corporate governance problem of firms that integrate different stakeholders becomes closer to the governance concerns in the cooperatives than to the traditional approach in capitalist companies.

Taking into consideration what has been previously explained and focusing now on the useful conclusions from the governance of firms, we observe that (1) the combination of incentives and monitoring mechanisms in Mondragón have been vital in defining a mission that maximizes collective wealth, and (2) it accounts for the impetus toward achieving this mission. This conclusion, drawn from the case study in which multiple tasks were undertaken, can be compared with the theoretical conclusions from other analyses of efficiency in contexts with multiple goals and with different stakeholders that participated in the monitoring process (Holmström, 1999; Rajan \& Zingales, 1998). Although the theory (Hart, 1995 ) indicates that the concentration of residual rights on one stakeholder enhances the collective efficiency (in comparison to shared ownership and control), some scenarios have been identified in which shared control entails more efficiency. This is particularly observed at a place of work where various tasks are undertaken and the results that are obtained concern different stakeholders.

Shared control contributes to reducing the intensity of incentives on the task of which the result is preferred by the one who makes decisions, in comparison with the intensity of incentives that would come out if one person gets all of the control. By reducing the intensity of these incentives, a general system of better-balanced (between the various tasks and the results) compensations is achieved with a positive impact on efficiency.

This result can be compared with the predictions of Tirole (2001), which indicated that concentrating control in the hands of just one person is preferable to shared control. His argument is based on the fact that allocating control in the hands of shareholders can bring about biased choices (in particular, maximizing share prices without taking into account the interest of workers, suppliers, clients, or the community), but this is, nevertheless, preferred to the costs associated with shared control and a multiplicity of objectives.

We believe that this argumentation does not consider the possibility of integrating shared control and a multiplicity of objectives. Under these circumstances, the manager's preference to economic results would be reduced and, at the same time, other objectives in the mission of the firm, which represent the interests of other stakeholders, would be equally taken into consideration. Likewise, the theory of property rights and that of incomplete contracts, along with their possible integration in the design of incentives when there are multiple tasks, open new possibilities for implementing shared control mechanisms in organizations in which stakeholders are involved.

Therefore, we present evidence contrary to Tirole's interpretation. First, it is not strictly true that in the absence of adequate indicators of the stakeholders' welfare, managers will always focus their attention on the maximization of the economic results, due to the fact that they are more readily measurable. Second, even if we entertain the possibility that there are policy costs to be incurred from shared control, we do not have enough evidence to show that those costs are higher than the agency costs or the costs of other governance-related problems present in a shareholder-oriented organization.

For that reason, we cannot conclude that if the MCC pursues a stakeholder-oriented approach in its mission, this will unmistakably weaken its competitive stand. Nevertheless, we have observed that it certainly demands much more elaborated governance solutions.

\section{NOTES}

1. The law foresees this problem and therefore regulates the formation of governing bodies, as is the case of the regulation concerning the creation of governing councils.

2. If workers are compensated with part of the total product according to workers' contributions to the cooperative (in terms of labor or specific investments), this total outcome will become a public good subject to the problem of free rider. Therefore, if a worker chooses some efficient contributions, he or she will be subject to an expropriation of wealth, because the marginal cost of the contribution will be higher than the marginal profit that he or she will receive in exchange (considering that other workers, pursuing solely their own interests, opt for the second-best solution).

3. The nonavailability of the "exit option" is a convincing hypothesis because the cooperatives participate in less competitive markets (Hansmann, 1999). In any case, if the "exit options" were to exist (i.e., the specific investment in human capital were not substantial), workers with high productivity would find better-paid jobs outside the cooperative, in accordance with their marginal productivity. Therefore, only the least productive workers would remain in the cooperative (Kremer, 1997). 
4. The more specialized the human capital is, or the greater the requirements of capital finance are in order to acquire physical assets, the more acute the problem of lack of risk diversification becomes.

5. Various inspections by the Bank of Spain pointed out such risk. This concern led to the recommendation that the bank be opened to third parties outside the group.

6. Integrated into salaries, it consists of advance payments, throughout the year, of the generated surplus in the fiscal year.

\section{REFERENCES}

Benham, L., \& Keefer, P. 1991. Voting in firms: The role of agenda control, size and voter homogeneity. Economic Inquiry, 29 (October): 706-719.

Ben-Ner, A., \& Jones, D.C. 1995. Employee participation, ownership, and productivity: A theoretical framework. Industrial Relations, 34 (4): 532-554.

Bonin, J.P., Jones, D.C., \& Putterman, L. 1993. Theoretical and empirical studies of producer cooperatives: Will ever the twain meet? Journal of Economic Literature, 31 (September): 1290-1320.

Craig, B., \& Pencavel, J. 1993. The objectives of worker cooperatives. Journal of Comparative Economics, 17 (2): 288-308.

Dow, G.K. 2001. Allocating control over firms: Stock markets versus membership markets. Review of Industrial Organization, 18 (2): 201-218.

Dow, G.K., \& Putterman, L. 2000. Why capital suppliers (usually) hire workers: What we know and what we need to know. Journal of Economic Behavior E Organization, 43 (3): 319-336.

Fama, E.F., \& Jensen, M.C. 1983. Agency problems and residual claims. Journal of Law E Economics, 26 (2): 327-349.

García-Cestona, M.A. 1996. La financiación de la industria. In Fundación Empresa y Ciencia (Eds.), Competir en Europa: 82102. Barcelona: Ariel.

Hansmann, H. 1988. Ownership of the firm. Journal of Law, Economics, and Organization, 4 (2): 267-304.

- 1990. The viability of worker ownership: An economic perspective on the political structure of the firm. In M. Aoki, B. Gustafsson, \& O. Williamson (Eds.), The firm as a nexus of treaties: 162-184. London: Sage.

. 1996. The ownership of enterprise. Cambridge: Harvard University Press.
1999. Cooperative firms in theory and practice. Finnish Journal of Business Economics, 48 (4): 387-403.

Hart, O. 1995. Firms, contracts and financial structure. Oxford: Clarendon Press.

Hirschman, A. 1970. Exit, voice and loyalty: Responses to decline in firms, organizations and states. Cambridge: Harvard University Press.

Holmström, B. 1999. The firm as a sub-economy. Journal of Law, Economics and Organization, 15 (1): 74-103.

Holmström, B., \& Milgrom, P. 1991. Multitask principal-agent analysis: Incentive contracts, assets ownership and design. Journal of Law, Economics and Organization, 7 (special issue): 24-51.

Jensen, M.C., \& Meckling, W.H. 1976. Theory of the firm: Managerial behavior, agency costs and ownership structure. Journal of Financial Economics, 3 (4): 305-360.

Kremer, M. 1997. Why are worker cooperatives so rare? Working Paper 6118, National Bureau of Economic Research, Cambridge, MA.

MCC (Mondragón Corporación Cooperativa). 1991. Annual report. Mondragón, Spain.

-1995. Compendio de normas en vigor del congreso de MCC. Mondragón, Spain.

Ormaetxea, J.M. 1997. Orígenes y claves del cooperativismo de Mondragón. Mondragón: Litografía Danona.

Prychitko, D.L, \& Vanek, J. 1996. Producer cooperatives and labormanaged systems, vols. I and II. Cheltenham, UK: Edward Elgar.

Rajan, R., \& Zingales, L. 1998. Power in a theory of the firm. Quarterly Journal of Economics, 113 (2): 387-432.

Shleifer, A., \& Vishny, R.W. 1997. A survey of corporate governance. Journal of Finance, 52 (2): 737-783.

Tirole, J. 2001. Corporate governance. Econometrica, 69 (1): 1-35.

Turnbull, S. 1995. Innovations in corporate governance: The Mondragón experience. Corporate Governance: An International Review, 3 (3): 167-180.

Whyte, W.F. 1995. Learning from the Mondragón cooperative experience. Studies in Comparative International Development, 30 (2): 58-67.

- 1999. The Mondragón cooperatives in 1976 and 1998. Industrial and Labor Relations Review, 52 (3): 478-481.

Whyte, W.F., \& Whyte, K.K. 1991. Making Mondragón: The grow and dynamics of the worker cooperative complex. Ithaca, NY: ILR Press.

Zingales, L. 2000. In search of new foundations. Journal of Finance, 55 (4): 1623-1653. 